\title{
Clinical and Echocardiographic Characteristics After Six Months of Sacubitril Valsartan in Chagas Heart Disease.
}

Clara Figueiredo ${ }^{1}$, Rodrigo de Melo ${ }^{1}$, Taina Viana ${ }^{1}$, Aline Queiroz de Jesus ${ }^{1}$, Tainara da Silva $^{1}$, Vitor da Silva ${ }^{1}$, William de Carvalho ${ }^{1}$, Daniela da Silva ${ }^{1}$, and Luiz Carlos Passos ${ }^{1}$

${ }^{1}$ Universidade Federal da Bahia

May 12, 2021

\begin{abstract}
Chagas cardiomyopathy is the most prevalent non-ischemic cardiomyopathy in Latin America, with high morbidity and mortality even today. Treatment of these patients is based on the use of medications for heart failure. This study evaluated a cohort of patients with Chagas heart disease who used sacubitril valsartan at a referral hospital for the disease in Brazil. After six months, there was a symptomatic improvement in these individuals assessed by the NYHA classification, with a $44.3 \%$ reduction in the absolute number of patients classified as III-IV in the period ( $\mathrm{p}$ 0.035), but without changes in the parameters on the echocardiogram for reverse ventricular remodeling and still high mortality rate and hospitalization. These results emphasize the importance of studying the use of sacubitril valsartan in chagas heart disease to better describe its effectiveness taking into account the peculiarities of these individuals.
\end{abstract}

\section{Hosted file}

Short Report - Chagas.pdf available at https://authorea.com/users/328591/articles/521743clinical-and-echocardiographic-characteristics-after-six-months-of-sacubitril-valsartanin-chagas-heart-disease

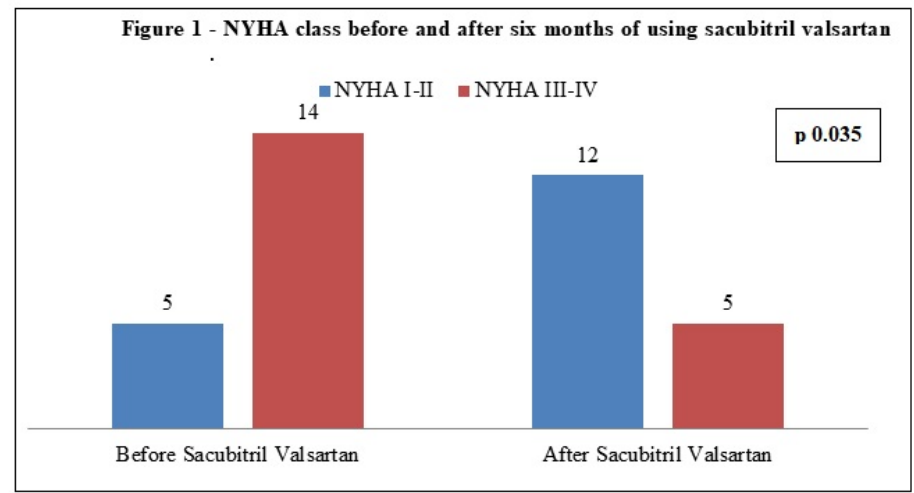

\section{Hosted file}


Tables-ChHD.pdf available at https://authorea.com/users/328591/articles/521743-clinical-andechocardiographic-characteristics-after-six-months-of-sacubitril-valsartan-in-chagasheart-disease 